\title{
Original
}

\section{Detection Method of Genetically Modified Papaya Using Duplex PCR}

(Received February 2, 2006)

\author{
Akihiro Yamaguchi*1, Kaori Shimizu*1, Takashi Mishima*1, Nobutaro Aoki*2, \\ Hideki Hattori*1, Hidetaka Sato*1, Nobuo UedA ${ }^{* 1}$, Takahiro Watanabe*3, \\ Akihiro Hino*4, Hiroshi Akiyama*3, ${ }^{\dagger}$ and Tamio Maitani*3 \\ (*1 Japan Food Research Laboratories, Chitose: 2-3, Bunkyo, Chitose-shi, Hokkaido 066-0052, Japan; \\ *2 Japan Food Research Laboratories, Tama: 6-11-10, Nagayama, Tama-shi, Tokyo 206-0025, Japan; \\ ${ }^{* 3}$ National Institute of Health Sciences: 1-18-1, Kamiyoga, Setagaya-ku, Tokyo 158-8501, Japan; \\ ${ }^{* 4}$ National Food Research Institute: 2-1-12, Kannondai, Tsukuba 305-8642, Japan; \\ ${ }^{\dagger}$ Corresponding author)
}

\begin{abstract}
A simple and rapid method for the identification of genetically modified (GM) papaya, derived from Line 55-1, was developed by modifying the Japanese official PCR method. Genomic DNA was directly extracted from the fresh fruit without the lyophilization step, using a commercial silica-based kit. To develop a duplex PCR method which simultaneously detects the GM papayaspecific gene and the intrinsic papain gene, the papain $2-5^{\prime} / 3^{\prime}$ (amplicon size; $184 \mathrm{bp}$ ) primer pair for the detection of the papain gene was newly designed within the region of the products $(211 \mathrm{bp})$ amplified using the papain $1-5^{\prime} /-3^{\prime}$ primer pair adopted in the Japanese official PCR method. To detect the GM papaya-specific gene, the primer pair Nos $\mathrm{C}-5^{\prime} / \mathrm{CaM} \mathrm{N}-3^{\prime}$ described in the Japanese official method was used. The DNA sequences of the GM papaya gene and the intrinsic papain gene were co-amplified using the PCR method in a single tube. The developed duplex PCR method allows the simultaneous detection of the products by means of agarose gel electrophoresis or microchip electrophoresis. The proposed method for GM papaya identification is simple and rapid.
\end{abstract}

Key words: genetically modified papaya; recombinant DNA; PCR; detection method; microchip electrophoresis; duplex PCR

\section{Introduction}

Genetically modified organisms (GMOs) are products of recombinant DNA technology, which can result in improved functional properties. Over the past two decades, tremendous advances have been achieved in genetically modified (GM) foods. The Ministry of Health, Labour and Welfare in Japan requires a mandatory safety assessment of GM foods. Since April 1, 2001, GM foods which have not been authorized can not be imported or sold in Japan. Therefore, qualitative detection methods for regulating unauthorized GM foods were required. The GM papaya with tolerance to the papaya ringspot virus (PRSV) has not yet been authorized in Japan, so identification of this GM papaya is required to prevent the import of unauthorized products. We have reported detection methods for GM soybean $^{1)}$, GM maize ${ }^{2)-4}$, GM potato (NewLeaf Plus, NewLeaf $Y)^{5), 6)}$ and GM papaya ${ }^{7)}{ }^{8)}$ (Line $55-1$ or its derivatives) using qualitative polymerase chain reaction (PCR) methods.

A qualitative PCR method ${ }^{7)}$ was developed to identify the GM papaya by individual amplification of the GM papaya-specific gene and the intrinsic papain gene. This method has been successfully applied to the fresh fruit, and authorized as a Japanese official PCR method. However, it is time-consuming, because it includes a lyophilization step prior to the DNA extraction. In addition, the final DNA concentration in the extract should be measured to ensure the use of appropriate amounts of the PCR template.

On the other hand, a histochemical assay for $\beta$ glucuronidase (GUS) activity expressed in the GM papaya was also authorized as an alternative approach for the Japanese official method ${ }^{9)}$. The histochemical method is simple and less costly. However, the assay requires manual excising of 12 seed embryos per sample, a labor-intensive task for which the time requirement increases in proportion to the sample number.

In this paper, we describe a novel rapid PCR method with simplified procedures of DNA extraction and PCR detection. 


\section{Materials and Methods}

\section{Samples}

The GM papaya (Rainbow, an $\mathrm{F}_{1}$ hybrid of the CP gene homozygous Line 55-1 X Kapoho) was obtained from the Ministry of Health, Labour and Welfare in Japan. Half-cut GM papaya fruits, stored for 2 years at $4^{\circ} \mathrm{C}$ in a sealed plastic bag, were used as the raw fresh fruits of GM origin. Non-GM papaya was purchased from a retail store in Sapporo City.

\section{Reagents}

The DNA extraction kit (DNeasy Plant Mini kit) was purchased from QIAGEN (Valencia, CA, USA). The DNA polymerase (AmpliTaq Gold) was purchased from Applied Biosystems (Foster City, CA, USA). Agarose (L 03 and Nusieve $3: 1$ ) was purchased from Takara Shuzo Co., Ltd. (Kyoto, Japan). The DNA size marker (100 bp DNA ladder) was purchased from New England Biolabs (Ipswich, MA, USA). A positive control plasmid DNA for GM papaya detection was purchased from Nippon Gene Co., Ltd. (Osaka, Japan). All other reagents were obtained as special-grade products. Water was purified using a Millipore Milli-Q Synthesis A 10 super water purifier and then autoclaved at $121^{\circ} \mathrm{C}$ for $20 \mathrm{~min}$.

\section{DNA extraction}

The genomic DNA was extracted using a silica-gel membrane-type kit (QIAGEN DNeasy Plant Mini). The raw fresh fruit was cut into pieces weighing about 100 $\mathrm{mg}$ and placed in $1.5 \mathrm{~mL}$ microtubes. The fresh fruit was homogenized with a pellet mixer (Treff AG, Degersheim, Switzerland) after the addition of $400 \mu \mathrm{L}$ of AP1 buffer with $4 \mu \mathrm{L}$ of RNase A. The subsequent procedures were according to the manufacturer's instructions. DNA was also extracted from $80 \mathrm{mg}$ of powdered freeze-dried fresh fruit as previously described ${ }^{7)}$. In both samples, the genomic DNA was finally eluted in $100 \mu \mathrm{L}$ of AE buffer or sterilized water and directly used as the PCR template. The DNA concentration was calculated from the UV absorption at $260 \mathrm{~nm}$.

\section{Duplex PCR}

The amplification reactions were carried out in a total volume of $20 \mu \mathrm{L}$ in $0.2 \mathrm{~mL}$ tubes containing GeneAmp PCR Buffer II (10 mmol/L Tris-HCl, pH 8.3, 50 mmol/L $\mathrm{KCl}$ ), $0.2 \mathrm{mmol} / \mathrm{L}$ dNTP, $3 \mathrm{mmol} / \mathrm{L} \mathrm{MgCl}_{2}$, newly designed papaya intrinsic primer pair $(0.1 \mu \mathrm{mol} / \mathrm{L}$ each of the papain $2-5^{\prime}$ ggcattctcagctgttgtaact/papain 2-3' tgggtaagtatttctgtagtggaa), the GM papaya-specific primer pair ${ }^{7)}(0.2 \mu \mathrm{mol} / \mathrm{L}$ each of NosC-5'/CaMVN-3'), 0.5 units Taq DNA polymerase and $2 \mu \mathrm{L}$ of the DNA extract. PCR was performed in a thermal cycler (GeneAmp PCR System 9700, Applied Biosystems) under the following conditions: an initial denaturation step at $95^{\circ} \mathrm{C}$ for $10 \mathrm{~min}$ followed by $35-40$ cycles at $95^{\circ} \mathrm{C}-30 \mathrm{sec}$, $55^{\circ} \mathrm{C}-30$ sec and $72^{\circ} \mathrm{C}-30 \mathrm{sec}$, finishing with a final extension step at $72^{\circ} \mathrm{C}$ for $7 \mathrm{~min}$.

\section{Agarose gel electrophoresis}

Duplex PCR products were separated using electrophoresis on 4\% Nusieve $3: 1$ agarose gel. Aliquots of $7.5 \mu \mathrm{L}$ of the PCR products were separated with Mupidalpha (Advance Co., Ltd., Tokyo, Japan) at a constant voltage $(100 \mathrm{~V})$ on $4 \%$ agarose gel in the TAE (40 $\mathrm{mmol} / \mathrm{L}$ Tris $-\mathrm{HCl}, 40 \mathrm{mmol} / \mathrm{L}$ acetic acid, and $1 \mathrm{mmol} /$ L EDTA, pH 8.0) buffer solution containing $0.5 \mu \mathrm{g} / \mathrm{mL}$ ethidium bromide. The gel was photographed with an M-085D instant camera (Polaroid Japan Co., Ltd., Tokyo, Japan) under excitation at $254 \mathrm{~nm}$ on a conventional UV-transilluminator, while the PCR products obtained by the Japanese official method were electrophoresed and visualized on a 2\% Agarose L03 gel using the same procedure as described above.

\section{Microchip electrophoresis}

The PCR products were also analyzed by a Hitachi SV 1210 microchip electrophoresis system with an SI1000 auto-sample processor (Hitachi Hitec Co., Ltd., Tokyo, Japan). Aliquots of $1 \mu \mathrm{L}$ of the duplex PCR products were electrophoresed using an i-SDNA12 kit (Hitachi Kasei, Tokyo, Japan) according to the manufacturer's recommendations (high-resolution mode, $120 \mathrm{sec}$ injection time, $270 \mathrm{sec}$ separation time and chip temperature $\left.25^{\circ} \mathrm{C}\right)$.

\section{Results and Discussion}

\section{Verification of genomic DNA extracted from papaya}

We attempted to extract directly the genomic DNA from the fresh papaya fruit using the silica-gel membrane-type kit without any lyophilization step. The final concentrations of the genomic DNA solution extracted from the GM and non-GM freeze-dried fresh papaya samples were approximately $10 \mathrm{ng} / \mu \mathrm{L}$ and those in the case of the non-GM fresh fruit were in the range of $6.5^{-7.0} \mathrm{ng} / \mu \mathrm{L}$. The lower yield of the genomic DNA extracted without lyophilization from the fresh fruit is considered to be due to the difference in the amount of sampling matrix (wet $100 \mathrm{mg} v$ s. dried 80 $\mathrm{mg}$ ). The final concentrations of genomic DNA solution extracted from GM papaya fresh fruit that had been stored for a long period (approximately 2 years) under refrigeration were less than $5 \mathrm{ng} / \mu \mathrm{L}$. This low yield can probably be attributed to chemical and/or enzymatic denaturation during prolonged storage. The stored GM papaya fruit used here may not be an appropriate model of GM papaya fruit, but was the only sample available, since GM papaya has not been authorized in Japan.

\section{Evaluation of PCR amplification}

Using the Japanese official PCR method, we examined whether PCR products could be amplified from the genomic DNA extracted from the papaya fruit or freezedried papaya fruit samples. For both the genomic DNAs, the $211 \mathrm{bp}$ band used for the identification of the intrinsic papain gene was clearly detected (Fig. 1). On the other hand, the $207 \mathrm{bp}$ band used for the identifi- 


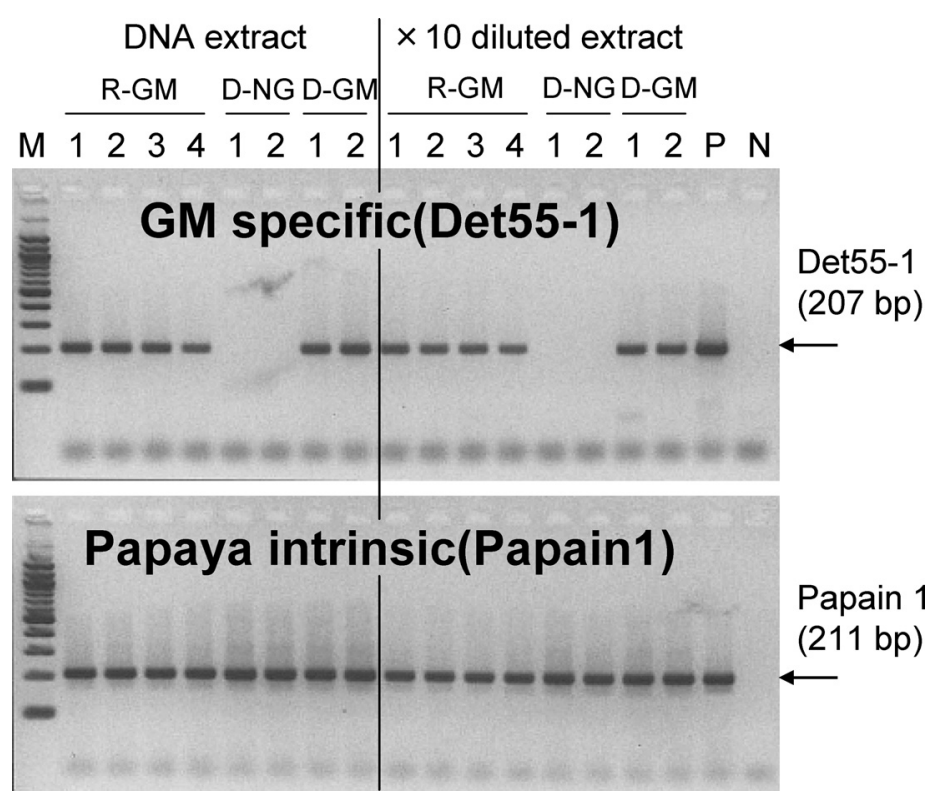

Fig. 1. Evaluation of genomic DNA by PCR amplifications from GM and non-GM papaya samples

R-GM: Raw GM fruit, D-NG: Dried non-GM fruit, D-GM: Dried GM fruit, M: 100 bp ladder marker, 1-2: Duplicate measurements, 1-4: Quadruplicate measurements, P: Positive control (Nippon Gene), N: Negative control (Water)

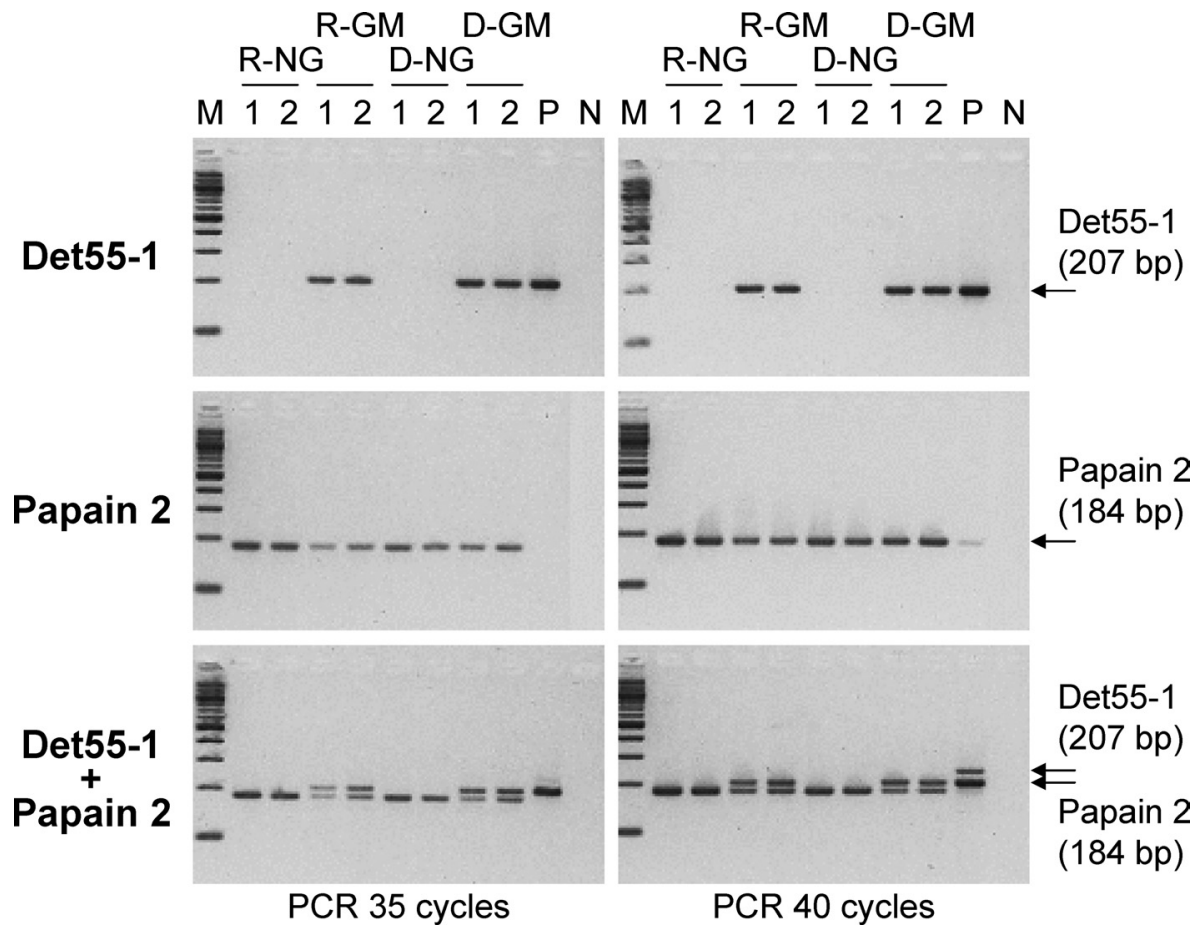

Fig. 2. Optimization of duplex PCR for GM specific and intrinsic papain genes

R-NG: Raw non-GM fruit, R-GM: Raw GM fruit, D-NG: Dried non-GM fruit, D-GM: Dried GM fruit, M: 100 bp ladder marker, 1-2: Duplicate measurements, P: Positive control (Nippon Gene), N: Negative control (Water)

cation of the GM-specific gene [Det55-1] was detected in the genomic DNAs extracted from the stored fresh GM papaya and the freeze-dried GM papaya fruit samples, but not in that from the non-GM papaya. These results suggest that the genomic DNA extracted from the denatured papaya fruit is still adequate for use as template DNA of the PCR, even though its quantity was significantly reduced.
Optimization of duplex PCR

We attempted to develop the duplex PCR method to simplify the procedures. To simultaneously detect the amplified products from the intrinsic papain gene and the GM-specific gene, the intrinsic papain primer pair, papain $2-5^{\prime}$ / papain $2-3^{\prime}$, was newly designed within the region of the $211 \mathrm{bp}$ products that were amplified using the primer pair for the detection of the papaya 


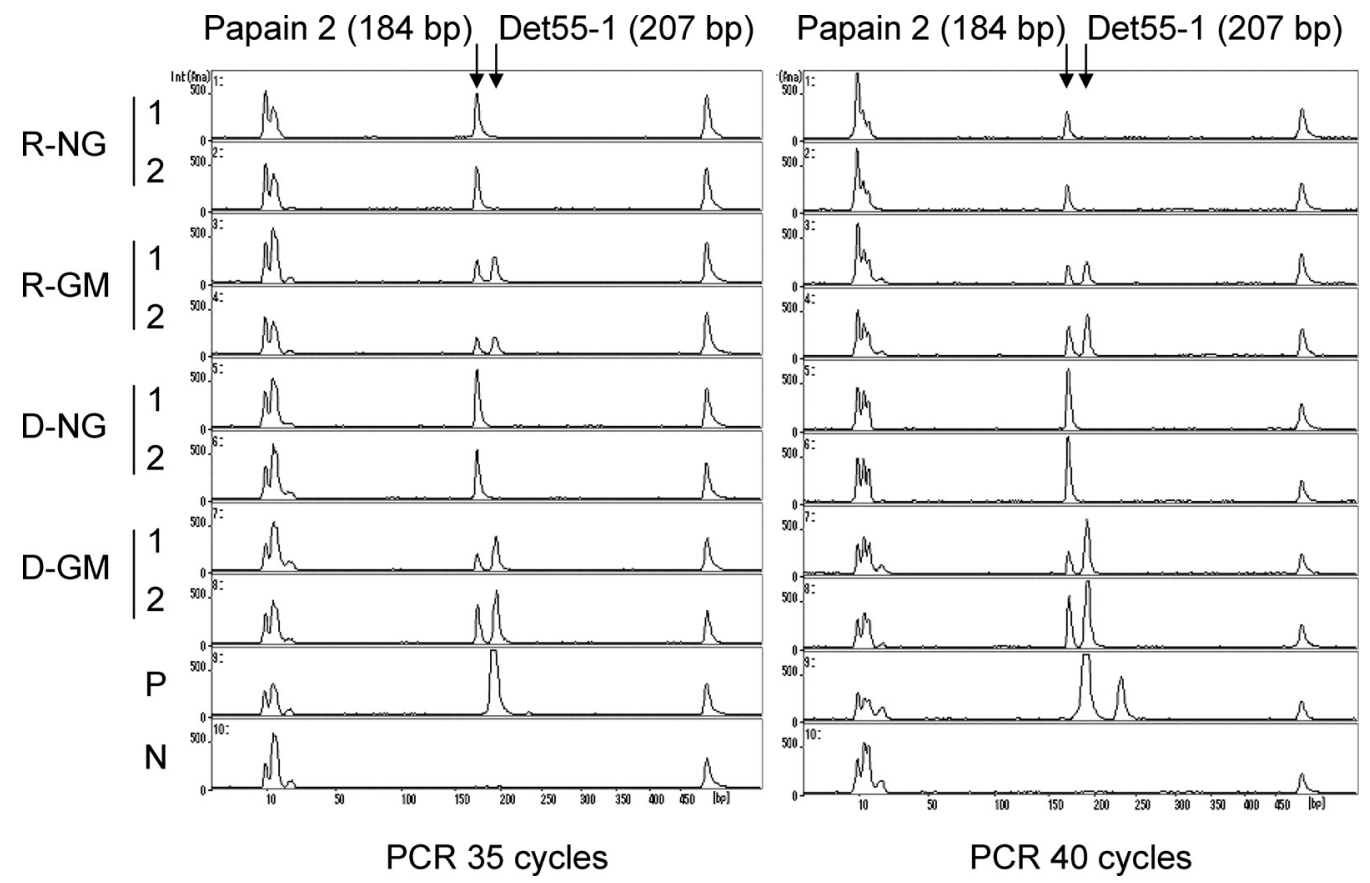

Fig. 3. Detection of the duplex PCR products by microchip electrophoresis

Electrophoresis was performed using a Hitachi SV1210 microchip system with the SI1000 autosample processor using the i-SDNA kit under the conditions described in the text. The abbreviations used are the same as in Fig. 2.

intrinsic gene by the Japanese official PCR method (Fig. 2). The ratio of the primer pair concentrations was examined in order to provide the best balance of both amplified product bands. Consequently, the optimum fluorescence intensities of the duplex amplifications were obtained at the concentrations of $0.1 \mu \mathrm{mol} / \mathrm{L}$ papain $2-5^{\prime} /$ papain $2-3^{\prime}$ and $0.2 \mu \mathrm{mol} / \mathrm{L}$ NosC-5'/ CaMVN-3' (Fig. 2). The PCR products of the GM papaya specific and the papaya intrinsic papain genes were analyzed within 3 min by microchip electrophoresis (Fig. 3).

In the case of only the commercial plasmid positive control in the duplex PCR detection, an unexpected amplified product of approximately $230 \mathrm{bp}$ was detected clearly at 40 PCR cycles. Also the amplified products of the papaya intrinsic papain gene were not detected at both 35 and 40 cycles in the positive control (Figs. 2 and 3). We consider that this would be due to the lack of the native papain gene sequence in the commercial plasmid positive control. The commercial plasmid positive control had been constructed in order to obtain the corresponding amplified products using the primer pair described in the Japanese official PCR method. The papain $2-5^{\prime}$ or $2-3^{\prime}$ primers appear to be annealed and amplified on the plasmid sequence including the artificial sequence to produce an unexpected amplified product band. However, this band is not the major product and appeared only as a trace band at 35 PCR cycles. Furthermore, it has never been detected in actual samples of GM papaya or non-GM papaya.

Since the PCR cycle number would be one of crucial factors in a DNA-based test, we also examined the appropriate cycle number of the duplex PCR. Increasing the number of PCR cycles after reaching a plateau of amplification increases the risk of contamination from amplified PCR products. We examined 30, 35 and 40 PCR cycles, and 35 PCR cycles appears to be enough to provide clear results, even with deteriorated DNA extracted from old raw papaya fruit (Figs. 2 and 3).

The results from the proposed method were completely consistent with those from the Japanese official PCR method (Fig. 2). The Japanese official PCR method required three days to analyze the recombinant DNA from the papaya, because it included the lyophilization step. On the other hand, the proposed method took approximately one day. Therefore, the proposed method is much faster than the Japanese official method.

In conclusion, the developed method is rapid and simple and would be suitable for identifying GM papaya. It should be suitable to monitor GM papaya at quarantine inspection centers for government regulation.

\section{Acknowledgments}

A part of this work was supported by a Grant for Scientific Research Expense for Health, Labour and Welfare Programs from the Japanese Government.

\section{References}

1) Matsuoka, T., Kawashima, Y., Akiyama, H., Miura, H., Goda, Y., Sebata, T., Isshiki, K., Toyoda, M., Hino, A., A detection method for recombinant DNA from genetically modified soybeans and processed foods containing them. Shokuhin Eiseigaku Zasshi (J. Food Hyg. Soc. Japan), 40, 149-157 (1999). 
2) Matsuoka, T., Kawashima, Y., Akiyama, H., Miura, H., Goda, Y., Kusakabe, Y., Sebata, T., Isshiki, K., Toyoda, M., Hino, A., A method for detecting recombinant DNA from genetically modified maize. Shokuhin Eiseigaku Zasshi (J. Food Hyg. Soc. Japan), 41, 137-143 (2000).

3) Matsuoka, T., Kuribara, H., Akiyama, H., Miura, H., Goda, Y., Kusakabe, Y., Isshiki, K., Toyoda, M., Hino, A., A multiplex PCR method for detecting recombinant DNAs from five lines of genetically modified maize. Shokuhin Eiseigaku Zasshi (J. Food Hyg. Soc. Japan), 42, 24-32 (2001).

4) Matsuoka, T., Kuribara, H., Suefuji, Y., Miura, H., Akiyama, H., Kusakabe, Y., Goda, Y., Isshiki, K., Toyoda, M., Hino, A., A detection method for recombinant DNA from genetically modified maize CBH351. Shokuhin Eiseigaku Zasshi (J. Food Hyg. Soc. Japan), 42, 197-201 (2001).

5) Akiyama, H., Sugimoto, K., Matsumoto, M., Isuzugawa, K., Shibuya, M., Goda, Y., Toyoda, M., A detection method for recombinant DNA from genetically modified potato (NewLeaf Plus potato) in snacks. Shokuhin Eisei- gaku Zasshi (J. Food Hyg. Soc. Japan), 43, 24-29 (2002).

6) Akiyama, H., Watanabe, T., Wakui, C., Chiba,Y., Shibuya, M., Goda,Y., Toyoda, M., A detection method for recombinant DNA from genetically modified potato (NewLeaf Y potato). Shokuhin Eiseigaku Zasshi (J. Food Hyg. Soc. Japan), 43, 301-305 (2002).

7) Goda, Y., Asano, T., Shibuya, M., Hino, A., Toyoda, M., Detection of recombinant DNA from genetically modified papaya. Shokuhin Eiseigaku Zasshi (J. Food Hyg. Soc. Japan), 42, 231-236 (2001).

8) Kikuchi, H., Watanabe, T., Kasama, K., Wakui, C., Matsuki, A., Akiyama, H., Maitani, T., Laboratoryperformance study of the notified methods to detect genetically modified papaya (55-1). Shokuhin Eiseigaku Zasshi (J. Food Hyg. Soc. Japan), 46, 21-27 (2005).

9) Wakui, C., Akiyama, H., Watanabe, T., Fitch, M. M., Uchikawa, S., Ki, M., Takahashi, K., Chiba, R., Fujii, A., Hino, A., Maitani, T., A histochemical method using a substrate of beta-glucuronidase for detection of genetically modified papaya. Shokuhin Eiseigaku Zasshi (J. Food Hyg. Soc. Japan), 45, 19-24 (2005). 